\title{
Deming's 14 points in modern higher education
}

\author{
Ekaterina Bagrova*, and Sergei Kruchinin \\ Industrial University of Tyumen, Department of applied mathematics and natural Sciences, 46 \\ Severnay st. Noyabrsk, Russia
}

\begin{abstract}
The paper discuss possibility to implement Deming's 14 points into Russian higher education, taking into account partially online development. The majority of these points can be used to improve the quality of higher education. However, there are many legal restrictions to public education that result in specific, measurable results that do not fully implement Deming's theories. Therefore, private universities have more potential to improve their quality then government schools. This fact explains the popularity of additional or professional courses in Russia as a substitute for regular education.
\end{abstract}

\section{Introduction}

Deming's points are common knowledge in quality management. They do not provide any particular instructions about what or how to do. Instead, they reflect Deming's philosophy about quality and effectiveness [1]. This philosophy assumes that quality is efficient. The main purpose of management is producing quality goods and services that lead to cost reduction, sustainable demand and effectiveness. Managers should not control the quality. Their main task is instead to constantly improve upon it. For this purpose, they must motivate and organize workers and the production process [2]. Each worker attempts to meet quality goals, motivated by pride in one's work. In other words, high-quality labor is the result of one's own self-esteem and pride in quality [3]. Managers must stimulate workers and organize processes. One of the most unexpected points of Deming's theory is that statistical research and even quality control are not useful, and may even harm organizational structures and key processes. The main ideas of Deming's philosophy are reflected in his 14 points. This paper considers the possibility of their realization in modern Russian higher educa is nottion. This discussion is especially important due to implementation of internet technologies in higher education. According to Deming's philosophy, new technology is not by itself beneficial, as it may substantially change production process, and does not inevitably lead to productivity increase. Instead, it may result in a decrease of quality and productivity [4].

\footnotetext{
* Corresponding author: bagrova.e.v@mail.ru
} 


\section{Methods}

In this study, Deming's 14 points are discussed in the context of modern online education in Russia. Each point is discussed in two key aspects. The first of them covers the possibility of implementing Deming's ideas into the Russian educational system. The most important issue is here Russian law, as some of these laws are in contradiction with Deming's points. Therefore, it is important to determine if it is realistic to use all of Deming's points. The second aspect is how to implement Deming's points specifically into Russian online education.

As a result, for each point, the possibility of implementation is discussed. Overall prospects of online education development in Russia are provided.

\section{Results}

\subsection{Create a constant purpose toward improvement}

According to this principle, materials and methods created nowadays must correspond with two simultaneous goals.

First, they have to be good enough to be effective for many years. This means that all basic materials must be high-quality. For instance, advanced courses will not significantly change for many years. Thus, their quality should be good enough to use for many years. Moreover, in each course there is a stable component, such as math. What are the quality criteria for such components? These parts have to be produced in a clear voice and language, without any modern slang words or other language-specific terms. They have to be addressed to students of a particular knowledge level, without repeating previous courses, but must build upon previously known information. Each course must end with student achievement of particular knowledge and skills, determined by testing.

Secondly, courses must be adaptable to new information technologies; new educational rules and requirements; and to new ideas and information.

Thus, the main criteria for a constant purpose are effectiveness over a long period of time, and adaptable to any future changes.

\subsection{Adopt the new philosophy}

This point is about understanding several educational needs. The first of these is students' actual needs. Undoubtedly, many students prefer the easy ways to obtain a degree. However, a university must provide quality education. This education should not only include the basics and necessities for each profession and specialization, it should also update education plans and develop students' skills. Such education is not intended to be easy, but to provide knowledge and skills to help students in their future careers and lives in general. For an example in practice, try to make some tasks for social media account development for PR students. Promote these into huge online events to demonstrate what real professionals should do; this is more effective than simple usage of outdated materials about paper publishing.

The second is a finer understanding of the first point. The first point is a philosophy everybody in a university must understand its goals. Undoubtedly, it is impossible to fully understand this without adequate salaries and a positive attitude toward employees. It is important to respect changes in their needs, according to new education formats and standards. 


\subsection{Don't rely on inspections to improve quality}

Quality is the process, not just the result [5]. It is important to provide a system of internal communications in the university which help to understand quality. For instance, each department can discuss current problems at least once a week or a month. These discussions will help each employee to stay in touch with current and long-term issues. The main aims of such discussions are to support each member of the team, understand their issues and collect suggestions for bottom-up quality improvement. Alternatively, this can be done using a simple online checklist instead of discussions. However, according to Deming's philosophy, the quality is the process; therefore it should be discussed.

\subsection{Use a single supplier for any one item}

Universities usually have multiple suppliers, with computer and other technical suppliers being key. Web development and book publishing are usually internal services of the universities. If not, these are also key suppliers. It is very important for a university to have a single, stable supplier for each field or specialty. Only such suppliers can provide longterm quality. Thus, it is very important to obtain long-term contracts instead of temporary tenders.

For online processes, it is important to buy stable services, use stable platforms and so on. Only long-term online links will lead to consistent online education development.

\subsection{Improve constantly and forever}

This point is about Deming's "Plan-Do-Check-Act" approach [6]. This is the model of stable quality improvement. For online higher education, this means that all innovations should be tested first on small student groups, then improved, and only afterwards implemented into the overall education process. It is extremely important to know which department bears responsibility for a particular online process. In the case of several departments working under one process, the primary department should be the one that must react the fastest to any issues in the process. The main purpose of such structure is to take under consideration any possible issues of the students interconnected with online educational format, including access, education and exam process maintenance.

The second aspect of this point is improving lecturers' qualifications. In the modern world, there are two main points. The first of them is transferring up-to-date knowledge to students. Usually, the best lecturers are scientists or people who are familiar with modern industry developments. Thus, it is extremely important to invite both scientists and industry experts into the educational process. It is easier to involve them in the online educational process when it can be combined with their main work activities. The second aspect is skills and competence development. While it is an important role of the lecturer or teacher to help students adapt to current reality, this issue should be addressed by professional lecturers and tutors. Their role is to develop students' personalities. To do this, they must lead some classes and create tasks to develop different competencies of students. Moreover, they can lead some coursework. In online education, they must communicate with students not just through video, lectures and online tests, but also through direct online dialogues.

\subsection{Use on-the-job training}

In the previous point, three types of lecturers were mentioned: scientists, industry specialists and tutors. For this point, all of these lecturers need to communicate well with each other to provide better educational quality and develop their own skills. Moreover, 
they need to understand each other's strengths and weaknesses to properly allocate diverse tasks among the team.

\subsection{Implement leadership}

This is one of the most difficult points to implement. At first, the university must provide the best employment conditions for each person to the best of their ability. There are two key issues here. First, each employee should be proud of their job. They should enjoy their work, be proud of the process, and always try to do their best work. Second, universities should also provide conditions for development of employees' personal growth and qualifications. This means that everybody has to do her or his best and, simultaneously, undergo a continuous process of self-development.

\subsection{Eliminate fear}

This point is quite similar to the previous one. It means that everybody must be included in the working process [7]. Each individual's opinion must be valued. Moreover, everybody must openly be able to express their opinion without any judgement.

Nowadays, universities are strong hierarchical systems. Personnel on the lower levels often cannot express their thoughts or influence the system development. Instead of this ineffective model, online higher education must modify this strong hierarchical principle. It should involve more outstanding specialists and provide openness for employees to express their thoughts to each member of community.

\subsection{Break down barriers between departments}

Build the "internal customer" concept - recognize that each department or function serves other departments that use their output [8]. It is extremely important to know which department bears responsibility for a particular online process. If several departments work under a shared process, the responsibility should be taken by the department that must react first if any issues arise.

Different departments must respect each other as internal customers. This means that they should formalize internal tasks, processes and responsibilities to be as clear as possible. Online communication helps with this point, as it allows multiple people or departments to work simultaneously on one document; this communication and collaboration are necessities online. Also, any online conversations can be easily recorded. Moreover, emails are a great opportunity to formalize internal tasks.

\subsection{Get rid of unclear slogans}

Unfortunately, this is one of the most difficult points to implement. This means that university management must understand the actual production processes very well. Moreover, they must understand the market their customers, and customers' current and future needs. On the basis of all these points, management should provide a clear strategy with concrete goals. Each goal is only achieved by meeting all of the points which lead to its realization. Moreover, it is extremely important that each point should define an action with measurable results. This management method ensures a very deep understanding of all the processes.

Modern technologies assist in measuring and calculating very complex processes. For instance, online lectures can be monitored to verify whether students understood it after the 
first viewing, or if students needed to review it several times; how often students move the mouse during lectures; and even determining which lecture components were the most impressive and attractive to students. All of these points will help to increase internal quality. However, only qualified management can truly analyze all the processes as a whole.

Unclear goals can be understood by different people in quite diverse ways. As a result, it is important to make them clear and unambiguous, in order to avoid internal contradictions within the team.

\subsection{Eliminate management by objectives}

The previous point is based on defining clear goals, which are important for management. However, they should not be implemented into communications with employees. In other words, the vast majority of the staff must be oriented in quality without any specific highlevel objectives. This is very far from the current Russian educational system. Online platforms provide a great opportunity to step back from the standard system. However, the most difficult part of this issue is government control, and determining measurable results on average, or even individually for each employee in the university.

\subsection{Remove barriers to pride of workmanship}

This point is also from the current Russian higher education system. Currently, everybody is paid according to their personal achievements. Thus, it takes a long time to raise quality without offering financial stimulus. It is a valid question here to ask whether it is possible to remove monetary incentives and implement Deming's motivation at all. Moreover, Russian labor law is on the side of workers, making it impossible to assert negative reinforcement (e.g., punishment). Thus, even in new schools and universities, many workers are unmotivated to work hard without financial gain, even if their salary would be much higher, on average, if there was a small change that an employer could remove them for substandard work.

Unfortunately, two of Deming's other principles, "implement education and selfimprovement" and "make transformation everyone's job", are also quite far from the reality of Russian higher education, as previously discussed.

\section{Discussion and conclusion}

There are many government restrictions for universities in Deming's points implementation [2]. The main restriction is that of government's assessment of universities' effectiveness through measurable objectives and specific statistics, which are far from Deming's understanding of quality [5]. There are also many restrictions in adding or removing personnel that result in the necessity to include monetary incentives [3].

This situation result in government universities unable to fully follow Deming's 14 points. As a result, private universities have more opportunities to develop and improve their quality. In this new era of online education, private universities can be more competitive and efficient. Moreover, the results of the article explain the popularity of additional and professional course attendance in Russia as an alternative to standard higher education. 


\section{References}

1. M.R. Frank., et al., Proceedings of the National Academy of Sciences, 116, 6531 (2019)

2. H. Saeedi, Imperial Journal of Interdisciplinary Research, 3(9), 1187 (2017)

3. W.E. Deming, MIT press (2018)

4. M. Arian, et al., Quarterly Journal of Nursing Management, 4, 45 (2016)

5. N.W. Baum, The Journal of Medical Practice Management: MPM, 34, 211 (2019)

6. Z. Cui, M. Li, E. Li, D. Ma, B. Zhao, Physica E: Low-dimensional Systems and Nanostructures, 104, 91 (2018)

7. A. Nursuhana, Y. Shu, Overview of Deming Criteria for Total Quality Management Conceptual Framework Design in Education Services (2019)

8. S.K. Breja, D.K. Banwet, K.C. Iyer, The TQM Journal, 28(3), 390 (2016) 